\title{
A Non-parametric Analysis of Convergence in ICT Industries
}

\author{
María-Jesús Mancebón ${ }^{1} \&$ Carmen López-Pueyo ${ }^{1}$ \\ ${ }^{1}$ Department of Applied Economics, Faculty of Economics and Business, University of Zaragoza, Zaragoza, Spain \\ Correspondence: María-Jesús Mancebón, Department of Applied Economics, Faculty of Economics and Business, \\ University of Zaragoza, Zaragoza, Spain. Tel: 34-976-761-809. E-mail: mjmance@unizar.es
}

\author{
Received: July 5, 2012 Accepted: September 5, 2012 Online Published: September 28, 2012 \\ doi:10.5539/res.v4n5p30 URL: http://dx.doi.org/10.5539/res.v4n5p30
}

The authors of this paper are grateful for the financial supports provided by the European Social Fund and by the Spanish Regional Government of Aragón (Research Project no. 269-165).

\begin{abstract}
The purpose of this article is to explore the relative merits of capital accumulation and efficiency catch-up in the convergence patterns of labor productivity in theICT (Information and Communication Technologies) sector in a set of developed countries. It is the first convergence analysis of ICT carried out from the non-parametric kernel approach and using an intertemporal data envelopment analysis (DEA) to estimate the efficiency of the analyzed countries. Special care has been paid to the dataset construction, using hedonic prices and unit value ratios because of the nature of the industry. The appropriate technology theory extended with non-immediate spillovers is the theoretical framework used to interpret the obtained results. These show thatlabor productivity, technology and efficiency have moved from a unimodal towards a bimodal distribution over time, beginning the $21^{\text {th }}$ century with two convergence clubs of countries. The conclusions obtained from these results show that while capital intensification offer opportunities to benefit from new knowledge developed by the leaders, assimilation of this knowledge is not immediate and its speed depends upon the social and technological capabilities of the followers. Policy decision-makers should be aware that the choice of the technology has to be complemented with the development of other actives to benefit from all its potentialities.
\end{abstract}

Keywords: ICT, labor productivity, hedonic prices, convergence clubs, DEA, kernel

\section{Introduction}

\subsection{The Problem: Relevance and Contribution to the Previous Literature}

Both the so-called fifth technological wave and the "new economy" the former has given rise to are supported by Information and Communication Technologies (Note 1). This "new economy" which has proven its capacity to improve productivity, economic growth and peoples' living conditions results from structural transformations taking place in production networks and society as a consequence of the increasing, extended and intense application of new technologies. This technology wave has a micro-electronic basis and can be exemplified mainly through the application of ICT to economic processes and social customs.

According to the OECD (2003), these technologies influence growth through three main channels, namely: 1) rapid productivity growth in ICT manufacturing and the increasing size of these industries; 2) intensification of investment in equipment, incorporating information and communication technologies, and subsequent improvement in labor productivity; and 3) spillover effects on productivity generated by these technologies.

In view of the relevance of ICTs, the aim of this article is analysing the convergence paths in the ICT industry during the last two decades of the $20^{\text {th }}$ century (1979-2001) in a set of developed countries (Canada, Finland, France, Italy, Spain and USA). The extension of the sample is limited by the availability of accurate data and the aim of correctly measuring productivity and having an actually homogeneous sample in terms of the methodology of the measurement of variables.

At the end of the 1980s there appeared several relevant contributions within the neoclassical model of the evolution of productivity and income per capita by countries (Abramovitz, 1986; Baumol, 1986; Baumol\& Wolff, 1988; Dowrick \& Nguyen, 1989). The interest in country convergence re-emerged in the 1990s following the introduction of new concepts such as " $\sigma$ convergence", " $\beta$ convergence" and "convergence clubs". 
Theoretical and empirical contributions generated a prolific debate on convergence following the contribution of Barro and Sala-i-Martin (1991, 1992 and 1995). Finally, two positions can be differentiated: while neoclassical models consider that disparities will tend to be reduced or even eliminated in the long run, endogenous growth theories show that disparities may continue, due to certain institutional factors. Furthermore, Quah (1993a, 1993b, 1996a, 1996b) introduced the new concept of convergence "clubs" into this debate, opening up the possibilities of polarization around different leader countries. Additionally, the multi-country Schumpeterian model of Howitt (2000) developed a theory of "club convergence" in which convergence occurs by means of technology transfer. To benefit from this, countries must spend on R\&D, as this is a necessary channel for technology transfer. To date, empirical evidence does not offer a conclusive result and the debate remains open.

In this context, this paper may be seen as a new contribution to this convergence literature. It is intended to fill some gaps of the previous studies applying a more accurately non-parametric methodology to a singular and relevant industry and interpreting the results in the context of a new theoretical framework: that of the Basu and Weil (1998) model, extended with non-immediate spillovers as Los and Timmer (2005) proposed (see next section). In this way, different national development paths shall arise, clarifying the relevance of having adequate or complementary actives and skills to exploit the investment in more advanced technologies.Capital deepening has been the traditional factor of growth, but in the new growth theories (Aghion \& Howitt, 1998, 2006) other factors such as technological capital, human capital, or institutions have proved their relevance. In this framework, assimilation depends upon the implementation of complementary reforms.

The main novelties of the present study are the following. First of all, empirical analysis shall be based on a non-parametric approach. A kernel analysis will be applied offering a convergence analysis of labor productivity, technological levels (Note 2), and efficiency. Previously, efficiency scores will be estimated using an intertemporal data envelopment analysis (Note 3). Acting in this way, a link between the macroeconomic convergence literature and the (deterministic) frontier production function literature, already established by Färe, Grosskopf, Norris and Zhang, Z. (1994) and some years later developed by Kumar and Russell (2002), is achieved. As these last authors point out, this non-parametric approach has advantages over the standard (regression-based) growth-accounting literature: it requires no specification of functional form, presumes no particular institutional or market structure, and does not require neutrality of technological change. Furthermore, using kernel analysis, the shift over time in the entire distribution of productivity is accounted for, in contrast with other convergence methods based on first moments of the distribution.

Secondly, and unlike other previous works which study aggregated economies (Kumar \& Russell, 2002; Los \& Timmer, 2005; Timmer \& Los, 2005; Färe, Grosskopf, \& Margaritis, 2006), this article follows a sectorial approach which allows a more accurate study of convergence/divergence patterns in OECD countries (Bernard \& Jones, 1996a). This is due to the fact that convergence driven by technology diffusion occurs at level of industries (or products) rather than at aggregate level. For that reason, if countries experience different patterns of industrial specialization, convergence at industry level might not be reflected in aggregate studies. On the other hand, sector-specific analyses allow a better approach to the empirical operationalization of the appropriate technology concept. In this article, the sector object of analysis is, as it has already been explained, ICT-producing manufacturing industries.

Thirdly, special attention is paid to the accurate measurement of the variables used in the article, due to the nature of the industry and the difficulties of international and intertemporal productivity analysis (OCDE, 2001). By one hand, Inklaar et al. (2003) expose the rapid quality change that suffers the ICT industry and so, the need to properly deflate current values by hedonic prices. On the other hand, Inklaar and Timmer (2007, 2009a, 2009b) offer a systematic analysis about the consequences of measurement error in productivity comparisons. The present study is the first, to our knowledge, that uses hedonic prices to have a proper measure to analyse convergence in ICT industry.

The rest of the article is organized as follows. The section 1.2 presents the theoretical framework; the second section sets up the methodological issues and the database used in the research; the third section exposes the results of the convergence analysis. The article finishes with a discussion section.

\subsection{Literature Review and Theoretical Framework}

The bulk of past studies about labor productivity have assumed technical efficiency and for that they have not considered its variation as a source of labor productivity growth and convergence. In the same way, this last one has been usually contrasted in its meaning of $\beta$ - convergence inside the neoclassical framework. However, the empirical evidence has prompted the development of new theoretical models and the use of empirical methods that allow to explain and to measure different patterns of convergence/divergence between countries. 
Earlier studies of the process of convergence in labor productivity did not consider the existence of technical inefficiency, attributing erroneously its changes to the effect of technical progress (Note 4). Only in the last decade, some papers began to consider changes in relative technical efficiency as a factor of convergence/divergence in labor productivity between countries (Note 5). Among these papers, only Kumar and Russell (2002), Färe, Grosskopf, and Margaritis (2006), Salinas-Jiménez, Álvarez-Ayuso and Delgado-Rodríguez (2006) \& Margaritis, Färe, and Grosskopf (2007) apply kernel density methods to study labor productivity convergence (Note 6). Nevertheless, they do not connect convergence analysis with the extended Basu and Weil theory as the present study does. This theory was first used (and extended) to interpret convergence analysis by Los and Timmer (2005), although not using kernel but $\beta$ convergence analysis.

Basu and Weil (1998) introduced a new theoretical model of international growth dynamics which may explain the patterns of international convergence and divergence observed in developed economies.

In this model, technology is a specific combination of production factors. For instance, in the case of two inputs, technologies are considered similar if capital/labor ratios are comparable. Higher capital/labor ratios denote more advanced technologies with higher maximum labor-productivity levels, while the maximum attainable labor-productivity for a given technology is called "target". As Basu and Weil (1998) put forward, there are two opposite forces working in growth processes. The first is the immediate spillover effect stemmed from the public nature of new knowledge on production technologies, an old assumption already pointed out by Solow (1956). The second is a new assumption which considers that new knowledge can only be "assimilated" by follower countries that produce with "appropriate" technologies (i.e., similar to the innovator's technology). Innovation is made by leaders and involves "localized" shift in a part of the production possibility frontier, not in the whole possibility frontier. Changed part is that related with the neighbourhood of the specific combination of production factors currently in use by leaders (Note 7). If innovation would take place at similar rates across technologies, Solow results would occur. However, Basu and Weil consider that innovation is "localized" at high-end technologies (Note 8) For this reason, countries operating low-end technologies may fall behind world's technology leaders. Because of this, capital intensification is a pre-condition for being able to benefit from international technological spillovers in the long run. Only when a country has increased its capital/labor ratios to levels comparable to those of countries in which most innovation takes place, such country can start benefitting from global technological change.

More recently, Los and Timmer (2005) applied this theoretical framework proposing a third determinant force on convergence and divergence patterns among countries: differences in the speed of spillover assimilation. Assimilation of new technologies is a costly (Note 9) and slow process. Following these authors, the assumption of immediate spillover of appropriate technology needs to be relaxed, entailing heterogeneous assimilation rates. The ability of a given country to assimilate appropriate knowledge should be considered as an additional and separated determining factor of growth, which works jointly with localized innovation and investment in capital. This ability depends on social and technological capabilities, using Abramowitz's terms.

\section{Methodology and Data}

In this section, a detailed explanation of the methodological issues and the data is carried out. Firstly, the methodology followed to accomplish the convergence measurement is described. Next, the method implemented to calculate the efficiency scores of each country is explained. Finally, a small section is devoted to disclose the sources of information and the sample.

\subsection{Convergence Measurement}

Convergence measurement may be carried out in different ways according to the concept or meaning attributed to such term (Note 10). A first meaning of convergence is related with the concept of homogenization which refers to a reduction in dispersion among a set of coutries in terms of some measure of performance. A second meaning of convergence is the concept of catch-up which refers to a narrowing in the percentage gap between the leading country's performance in the studied variable and that of the other countries in the sample. Barro and Sala-i-Martín (1992) coined the term $\sigma$-convergence and $\beta$-convergence respectively to refer to these two concepts.

Although, homogenization and catch-up are concepts of considerable relevance, reality is likely to provide cases in which relationships are more complex than pure homogenization or catch-up. For instance, the leader can pull ahead of the pack with the followers catching up only after considerable delay or most followers may pull closer to one another, but not to the leader. The importance of considering the entire dynamic of cross-sectional productivity distribution is emphasized by Quah (1996c \& 1997). As this author point out, convergence analysis relying on the first moments of a distribution cannot capture this dynamic. To evaluate the mobility patterns or 
intra-distribution dynamics it is necessary to resort to measurement tools such as kernel density functions. These functions are a non parametric method performing direct estimations of density functions. Using this tool to measure convergence allows us to maintain methodological coherence with the non-parametric approach (DEA) used in the present article to measure the efficiency of the countries (see next section).

For all these reasons, non-parametric kernel density methods will be used to determine shape and mobility dynamics in labor productivity $(\mathrm{Y} / \mathrm{L})$, capital/labor ratio $(\mathrm{K} / \mathrm{L})$ and efficiency score $(\mathrm{EFI})$ distributions over time. Homogenization and catch-up concepts have their corresponding measurement by applying kernel density functions. When the shape of the estimated density functions shows that probability mass tends to be more concentrated around a certain value over time, convergence (homogenization) is achieved. In contrast, the opposite outcome (divergence as heterogenization) would imply probability mass being increasingly spread across a wider range. Again, when probability mass tends to be more concentrated around the leader value, convergence (catch-up) occurs. Moreover, there are lots of additional outcomes such as different modes emerging or vanishing with different economic implications. Despite the fact that the dynamic performance of a distribution may not offer a clear pattern towards homogenization or heterogenization, intra-distribution mobility may show catch-up patterns. For instance, a general divergence (heterogenization) pattern may occur with an only group catching-up with the leader. In addition, changes in relative positions may be taking place without being reflected in the shape of density functions.

There is a wide variety of tools to estimate density functions non-parametrically. Histogram is the simplest one; however, its shortcomingssuch as having to choose an origin and bin width do not always provide accurate data-view. In contrast, kernel smoothing provides more accurate data analysis, needing no data parametric structure (unlike histograms). Although it is not the only method for uncovering data structure, its advantages make it the most widely applicable method on multiple variables, while its attributes are easy-to-understand (Note 11).

A kernel density estimate of a univariate density $f$ based on a random sample $X_{i}, \mathrm{i}=1, \ldots n$ is:

$$
\hat{f}_{h}(x)=(n h)^{-1} \sum_{i=1}^{n} K\left(\frac{x-X_{i}}{h}\right)
$$

where $h>0$ is bandwidth (or window-width) and $K$ denotes the kernel function for which the normal (Gaussian) one has been chosen (Note 12). Bandwidth $h$ determines the smoothness of estimated density, with a small $h$ leading to an estimate with high variability and a large $h$ to a smoother density estimate. The kernel density estimate of a series $\mathrm{X}$ at a point $x$ is estimated by equation (1). This equation shows how smoothing is performed, by awarding a lower weight to observations $X_{i}$ that are further from the point under evaluation. In our empirical application, $\mathrm{X}_{\mathrm{i}}$ will refer firstly to the $(\log )$ level of labor productivity in country $i$ in a particular time period. The choice of bandwidth is critical to determine shape of density. Silverman's (1986) method will be applied to determine optimal window-width for labor productivity levels over time, with a bracket option of $+/-0.5$ optimal $h$ to show estimations' sensitivityto bandwidth. The same steps will be applied to capital intensity and efficiency levels.

\subsection{Efficiency Measurement}

The DEA technique, based on mathematical programming, has evolved considerably since it first appeared in the seminal paper of Charnes, Cooper and Rhodes (1978). Specifically, multiple extensions of the initial model have been attempted to adapt the mathematical formulation and the process of obtaining efficiency indices to the peculiarities of the particular sector analyzed, to the nature of the variables constituting the analysis, or to the aims of the research in question (see Cooper, Seiford, \& Zhu, 2004; Thanassoulis, 2001).

From among the different proposals provided by the literature, the approach suggested by Tulkens and Van den Eeckaut (1995) to constructing reference production sets from alternative time-related observations subset is of particular interest for the task at hand. These authors explain that in the presence of a time dimension in the data, the estimation of the efficiency scores may be alternatively accomplished on a contemporaneous production set or on a sequential one. The first consists of comparing the data of the evaluated unit with a reference production set constructed at each point in time $t$ from the observations made at that time only. In this approach it is supposed that the frontier in each period envelops the observations from this period only. Under this assumption the technology of previous periods may be unfeasible in the following periods, that is, sometimes the frontier may move inwards indicating some "technical regress" (Shestalova, 2003). The second possibility (sequential 
approach) consists of evaluating the efficiency of each unit in time $t$ with reference to a frontier empirically constructed from the data previous to that time $t$ corresponding to all of the evaluated units. In this last way it is assumed that all the preceding technologies are also feasible. The frontier in a certain time envelops all data points observed up to this time, which eliminates the possibility of registering any regress by definition.

The choice of one of these approaches logically influence the way in which the empirical estimations of the efficiency scores are calculated. In the contemporaneous approach these scores are obtained by means of the solving of DEA mathematical program problems like the one in equation 2:

$$
\begin{aligned}
& \operatorname{Max} . \theta_{Z}=\operatorname{Max}\left[D_{0}^{t}\left(x^{t}, y^{t}\right)\right]^{-1} \\
& \theta_{Z}, \lambda \geq 0 \\
& \text { s.a. } \\
& \lambda X^{t} \leq X_{Z}{ }^{t} \\
& \lambda Y^{t} \geq \theta_{Z} Y_{Z}{ }^{t}
\end{aligned}
$$

where $\mathrm{X}$ and $\mathrm{Y}$ are respectively the $(m \times n)$ and $(s \times n)$ vectors of the $m$ inputs and the $s$ outputs of the $n$ evaluated observations, $\theta_{Z}$ the efficiency score of unit $Z$, and $\lambda$ is a $(n \times l)$ vector of non-negative scalars.

In the sequential approach these problems are converted into problems like that in equation 3

$$
\begin{aligned}
& \operatorname{Max} . \theta_{Z}=\operatorname{Max}\left[D_{0}^{t}\left(x^{t}, y^{t}\right)\right]^{-1} \\
& \theta_{Z}, \lambda \geq 0 \\
& \text { s.a. } \\
& \lambda\left(X^{t_{0}}, X^{t_{0+1}}, \ldots, X^{t}\right) \leq X_{Z}{ }^{t} \\
& \lambda\left(Y^{t_{0}}, Y^{t_{0+1}}, \ldots \ldots, Y^{t}\right) \geq \theta_{Z} Y_{Z}{ }^{t}
\end{aligned}
$$

Where the superscripts of the $\mathrm{X}$ and $\mathrm{Y}$ vectors denote the temporal period (which varies from time $t_{0}$ to time $t, t$ being the year under evaluation).

The solution of mathematical programming problems like that in equation 3 allows us to calculate the value of the distance- functions, $D_{0}^{t}\left(x^{t}, y^{t}\right)$, to each observation (country in our case), that is to say, the reverse of the efficiency productive score $\theta$ in the Farrell (1957) sense. The value of $\theta_{Z}$ corresponds to the efficiency score of country $Z$, i.e., the ratio between the maximum output achievable (value added $\mathrm{Y}$ on the frontier) from the physical capital stock (K) and annual working hours (L) used by this country and the actual output produced by it. This ratio represents the distance of country $Z$ from the frontier of best practices. In problem 3 the reference frontier of estimations is the sequential one which aggregates the best practices from the beginning of the period under analysis (see the left hand of the restrictions of problem 3).

The solution of equation 3 is the way that will allow us to achieve the variable EFI whose convergence pattern we analyze in section IV (Note 13). The sequential approach is especially attractive to the analysis carried out in our paper given that in the sector analyzed (ICT industries) the hypothesis of technical regress seems difficult to defend from a knowledge perspective on technology, as it would involve forgetting (Timmer \& Los, 2005). Additionally, the use of ansequential approach increases the number of observations taken into consideration when constructing the reference production frontier (Shestalova, 2003), something quite important in our empirical analysis, given the reduced size of the sample of countries. This approach is very innovative within the field of literature on economic growth. Up to date, it has only been applied in Los and Timmer (2005), Timmer and Los (2005) and Henderson and Russell (2005), all of them at aggregate level.

\subsection{Sources of information and the Sample}

To finish the presentation of the empirical issues on which our estimations are based, we devote this section to briefly explain the sources of information and construction process of the variables.

As it was said in the introduction, the analysis of the ICT industry is referred to the last two decades of the $20^{\text {th }}$ century (1979-2001) and to a selected group of developed countries: Canada, Finland, France, Italy, Spain and USA. Due to the nature of ICT industries, many measurement problems arise when a true deflator and a PPP rate are required. Thus, the sample has been selected on the basis of the homogeneity of the methodology used to measure the variables employed in developing the present study 
ISIC (InternationalStandard Industrial Classification) 30-33 sector is considered as the ICT-producing manufacturing industry along the present article. As Pilat, Lee and Van Ark (2002) point out, more detailed breakdowns, as demanded by OECD (2002) through its definition of the ICT sector, entail some measurement problems when estimating value added in constant prices.

The variables used in the convergence analysis are labor productivity $(\mathrm{Y} / \mathrm{L})$, technology (capital intensity K/L, in the sense of Basu and Weil, 1998) and efficiency (EFI). These last have been estimated by means of DEA.

The value added $(\mathrm{Y})$ is measured following a careful process. Data on gross value added $(G V A)$ are taken from the STAN (Structural Analysis) database of the OECD. We shall apply the following adjustments, bearing in mind that the industry under study is very sensitive to measurement problems and the sample considers different countries and years. Firstly, we shall apply hedonic prices to deflate value added. Secondly, we shall use unit value ratios (UVRs) to convert value added into dollars. Thirdly, the value added of each country must be adjusted by the output gap in order to avoid procyclical behaviour of labor productivity. Next, each stage of this adjustment process is explained in more detail.

Pilat and Lee (2001) show, that the use of hedonic vs. traditional deflators produces clear differences in the performance of economics variables of ICT goods which are so much exposed to quality changes. Hedonic prices available in the Industry Labour Productivity Database of the GGDC (Groningen Growth and Development Centre) were used as the basis for calculating the aggregate deflator ofsector 30-33, by means of a Törnqvist chained index. The methodology applied for calculating aggregated hedonic deflators follows that proposed by O'Mahony and Van Ark (2003) to avoid substitution bias introduced by fixed weighted price indices when calculating $G V A$ at constant prices when the structure of a sector varies over time.

Since we work with different countries, we shall use unit value ratios (UVRs) to convert their value added into dollars. UVRs are better measures to approximate real parities in this case (Note 14). The figures of $G V A$ we have expressed in the 1997 monetary units of the different countries are subsequently converted into 1997 US dollars by using the unit value ratios (UVRs) provided by the GGDC in Manufacturing Productivity and Unit Labour Cost Database.

Next, given that Scarpetta, Bassanini, Pilat and Schreyer (2000) highlighted that the different position of the countries in the cycle is one of the inherent complications in international comparisons of production levels and short-term economic growth, we decided to calculate the trend behaviour by using the procedure of Hodrick-Prescott (1997).

Concerning to capital $(\mathrm{K})$, gross fixed capital formation at current prices was taken from the STAN database. The variable was expressed in real units from 1997 and converted into US dollars of the same year by using the gross fixed capital formation PPP of the different countries calculated for OECD. With these figures, accumulated stocks of physical capital $(\mathrm{K})$ were calculated by applying the perpetual inventory method frequently used in empirical literature.

The labor factor (L) was approximated by the number of hours worked in the ISIC 30-33 sector of the countries analysed, information published by the GGDC.

Finally, the efficiency scores (EFI) were estimated through an intertemporal DEA method (see the former section) using the previous variables: value added $(Y)$ as output and the physical capital stock $(K)$, and annual working hours $(L)$ as inputs.

\section{Results}

As it was said in section II, Basu and Weil (1998) consider the existence of two opposed sources in growth processes: the spillover effect driving towards convergence and localized innovation driving towards divergence if countries operate with inappropriate technologies (not similar capital/labor ratios to those of the leaders). On the other hand, Los and Timmer (2005), considering that spillovers are not immediate due to the different social or technological capabilities of recipients countries, find that differences in the speed of knowledge assimilation is another factor of divergence. This theoretical framework is used to interpret the results of the convergence analysis of labor productivity (Y/L), capital intensity $(\mathrm{K} / \mathrm{L})$ and efficiency $(\mathrm{EFI})$.

The application of the kernel density methods previously explained to the data of the ICT producing industry in the selected developed countries allows us to conclude a progressive movement towards two convergence clubs in terms of labor productivity along the period 1979-2001, as well as to disentangle the possible sources of this movement. Certainly, the evolution of labor productivity distribution is conditioned by the distributions over time of capital/labor ratio and efficiency distribution, as Kumar and Russell, 2002, explain (Note 15). Efficiency score is the distance between the labor productivity of a country and that of the frontier country both having a 
similar capital/labor ratio (Note 16); in consequence, efficiency score over time depends on the movements of the reference frontier country (innovation) and the movements towards the frontier that the follower country makes (catch-up).

The distribution (smoothed histograms of the logarithm of labor productivity, i.e. LNPROD) for the crosssection of countries over time is shown in Figure 1, after axis and bandwidth unifications have been applied (Note 17).

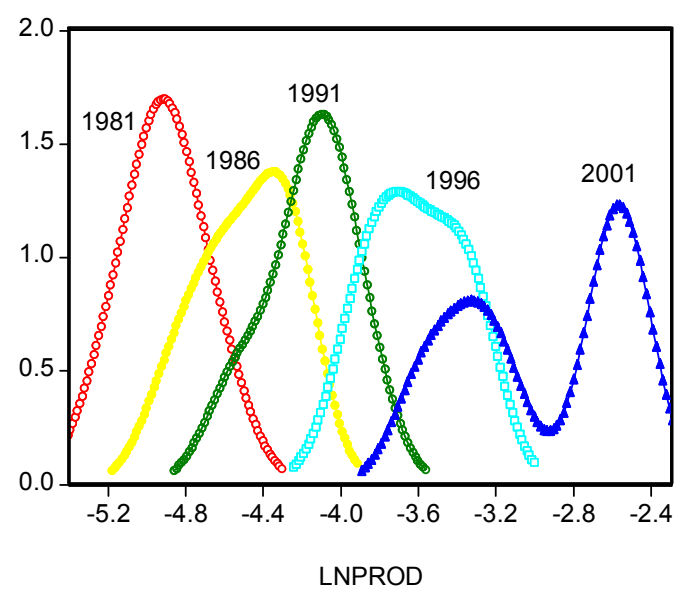

Figure 1 . Kernel density (normal, $\mathrm{h}=0.1570$ )

There is evidence to suggest a labor productivity improvement marked by rightward shifts in the modes of the respective distributions over time. The probability mass of the distribution has spread and the range of the density function has increased. It seems from empirical kernel estimates that the distribution of labor productivity shifted from unimodal in 1981 to bimodal by 2001. Regarding the intradistribution movements, at the beginning France occupied the first position and Spain the last one, while the remainder countries were placed around the mode (See Table 1). Spain remains in the last position over time while USA, from penultimate position, goes forward until reaching the top in 2001. In this year it can be found that the high-productivity club includes USA, Finland and France. Scarpetta et al. (2000) already showed that Finland and USA already appeared between the countries in which ICT-producing industries have had more labor productivity growth. The second group of countries, or low-productivity club, consists of Canada, Italy and Spain (Note 18).Then neither homogenization nor catch-up has been place as a general trend in the ICT sector of these countries. Bimodality at the beginning of the century is also the result found by Margaritis, Färe and Grosskopf (2007) in OECD countries (1980-2001). However their paper uses data of the whole economy of each country, while our data are taken from a single sector, and sectorial and aggregated tendencies can show very different paths. Kumar and Rusell (2002), for a sample of developed and underdeveloped economies in years 1965-1990 sustained the hypothesis of bimodality in aggregated labor productivity at the beginning of nineties. Similarly to our results, Färe et al. (2006) - for the period 1965-1998 - and Salinas et al. (2006) - for the period 1980-1997 -, estimated unimodal aggregated labor productivity distributions for EU countries in the second half of the nineties.

Table 2. Labour productivity levels (LN)

\begin{tabular}{lcccccc}
\hline & LNPROD81 & LNPROD82 & LNPROD86 & LNPROD91 & LNPROD96 & LNPROD01 \\
\hline Finland & -4.840732638 & -4.828290338 & -4.296886151 & -4.103147009 & -3.572901628 & -2.566960073 \\
France & -4.614006227 & -4.558708 & -4.230250823 & -3.877217317 & -3.375697309 & -2.614584772 \\
Italy & -4.843628727 & -4.764899312 & -4.350970475 & -4.100022285 & -3.696749974 & -3.351909929 \\
USA & -4.990231055 & -4.905754851 & -4.566991753 & -4.074737951 & -3.321563551 & -2.515100785 \\
Canada & -4.968174563 & -4.820032085 & -4.647915156 & -4.291732897 & -3.807248385 & -3.178450422 \\
Spain & -5.200199485 & -5.199648495 & -4.866951223 & -4.547325604 & -3.932621765 & -3.578217475 \\
\hline
\end{tabular}




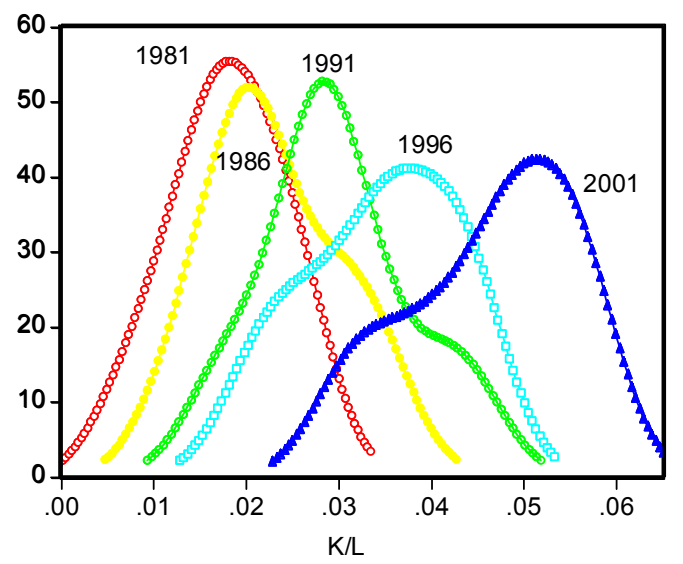

Figure 2. Kernel density (normal, $\mathrm{h}=0.0045$ )

Next, applying kernel analysis over capital intensity and relative efficiency we can show the possible sources of labor productivity bimodality. By applying kernel analysis to capital/labor ratios, it seems that technology distribution shifted from unimodal in 1981 to bimodal by 2001, as shown in Figure 2. The probability mass spread and the increase in the range of the density function provides evidence of technological divergence in the ICT industry. Rightward shifts in the modes of the respective distributions over time simultaneously suggest a process of capital intensification. Analysis of individual countries and their mobility within the cross-sectional distribution shows that France and Italy began in a first and second position, being gradually nearly overtaken by Spain and USA (See Figure 2 and Table 2). This last country developed a great process of capital intensification reaching the first position. Finally, USA and France, followed by Italy and Spain, are in the club of more capital/labor technologies, while Finland and Canada rest on a less intense capital use. In sum, technological catching-up with high-end countries has not been a general pattern, which is a prerequisite for being able to benefit from international spillovers.

Table 3. Capital-labor ratios

\begin{tabular}{lcccccc}
\hline & $\mathrm{K} / \mathrm{L} 81$ & $\mathrm{~K} / \mathrm{L} 82$ & $\mathrm{~K} / \mathrm{L} 86$ & $\mathrm{~K} / \mathrm{L} 91$ & $\mathrm{~K} / \mathrm{L} 96$ & $\mathrm{~K} / \mathrm{L} 01$ \\
\hline Finland & 0.017935525 & 0.018605854 & 0.020469221 & 0.027668842 & 0.028109026 & 0.039724415 \\
France & 0.024495528 & 0.026481830 & 0.033633653 & 0.042778417 & 0.044587668 & 0.05429240 \\
Italy & 0.023792983 & 0.024513347 & 0.02868110 & 0.033658736 & 0.042161936 & 0.049458871 \\
USA & 0.016524424 & 0.017966305 & 0.021142458 & 0.027162676 & 0.036333768 & 0.056702132 \\
Canada & 0.008705502 & 0.010192108 & 0.013517525 & 0.018128885 & 0.021929826 & 0.031859344 \\
Spain & 0.015814866 & 0.015861521 & 0.019640315 & 0.028030994 & 0.034631374 & 0.046814612 \\
\hline
\end{tabular}

As Basu and Weil (1998) points out, new knowledge can only be assimilated by follower countries that produce with appropriate technologies, that is, similar capital-labor ratios to the innovator's technology. Two clubs have emerged in this period in terms of capital intensity, conditioning the spillover potential of the follower countries. The appearance of two clubs in performance could point to the difference in industrial specialization within the ICT-sector, and consequently in their different capital deepening. As Pilat et al. (2000) argue, much of the ICT hardware is highly concentrated because of its large economies of scale and high entry costs; while, some countries mainly produce peripheral computer equipment where technical progress is more limited than in the production of computers and semi-conductors. As innovation is made by high-end technologies countries, not operating in the neighbourhood of their correspondent capital intensity levels carries on that followers cannot start benefiting from global technological change. Dissimilar to Kumar and Russell (2002) for previous years and the whole economy, capital accumulation does not appear as the main responsible for the emergence of the bimodal distribution of labor productivity in ICT industry because the member countries of each distributions 
groups are not the same. However, the effective realization of the spillover potential corresponding to each capital/labor ratio can be reflected in efficiency scores, as we will show subsequently.

The kernel analysis of the efficiency scores over time shows the achievement of that spillover potential. Results are shown in Figure 3 and Table 3, showing the evolution of efficiency distribution for some years. The most important feature is a trend toward divergence, as probability mass tends to be increasingly spread across a wider range. Furthermore, dispersion of relative efficiency levels has increased. Interpretation is a trend opposite to catching-up, as the gaps between the frontier countries' efficiency level and that of others become wider. Gradually, the features dominating the final situation are not only a much higher dispersion level but also a very different shape from the initial situation. Hence, while at the beginning unimodality is clear, it becomes a twin-peaks distribution by 2001. It is as well to remember that efficiency scores are the result of comparing the performance of each country with the best practice by using the same technology (capital/labor ratio). The observed backward movement in mode values (especially in 90s) could be explained by technological improvement (capital intensification) or by localized shift in the global frontier (innovation). Because of these, the distance to the new frontier usually increases and also does the potential to receive spillovers; but that potential could not be developed depending on the different abilities of countries to assimilate knowledge spillovers if they lack the appropriate social and technological capabilities. This behaviour would give support to the hypothesis of heterogeneous assimilation rates pointed out by Los and Timmer (2005).

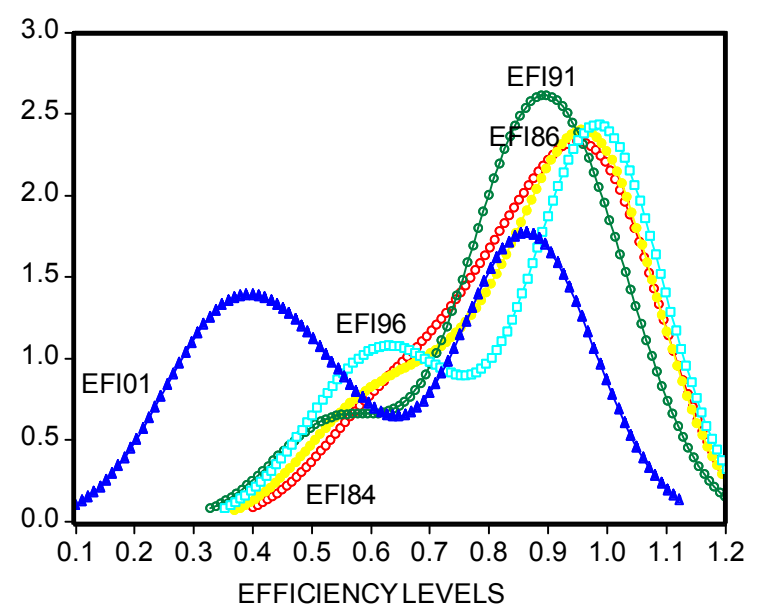

Figure 3. Kernel density (normal, $\mathrm{h}=0.1068$ )

This transition in the ICT industry kernel distribution can occur simultaneously with changes in the countries' relative efficiency scores ranking (See Table 3). This is quite plausible in an industry undergoing rapid change, where countries may be more or less efficient than others in any particular year, but this ranking may not stand still. Beginning with a unimodal distribution headed by France, Canada and Finland (efficiency scores equal to unity), followed by USA, Italy and, in the last position, Spain, a bimodal distribution is reached in 2001 with USA, Finland and France included into the most efficient set, and Canada, Italy and Spain as the least efficient set. Spain shows persistence as it remains at the last position, even widening its distance to the frontier over time. Italy is gradually losing efficiency and, as it moves back in the efficiency score ranking, it brings into line with the group of follower countries. Canada, maintaining an efficient position since the beginning, finally also joins this group as a consequence of capital intensification (see Table 2). USA takes off in the 1990s, winning positions in this efficiency ranking. It is worth to underline the different paths followed by Canada and Italy. Canada accomplishes great capital intensification in the 1990s, which explains its temporary efficiency loss. On the contrary, Italy has carried out a relatively small capital intensification effort in last years, remaining then in a low relative efficiency position. As in Salinas et al. (2006) for the whole European economies, efficiency movements appear to be the main factor behind labor productivity bimodality at the end of the past century: countries in the high and low clubs are the same in productivity and efficiency distributions. The stories of Finland, Canada and Spain obtained for the aggregated economy in Margaritis et al. (2007) are similar to our results in terms of the efficiency distribution in ICT. 
Table 3. Efficiency levels*

\begin{tabular}{ccccccccccccccccccc}
\hline & 84 & 85 & 86 & 87 & 88 & 89 & 90 & 91 & 92 & 93 & 94 & 95 & 96 & 97 & 98 & 99 & 00 & 01 \\
\hline Finland & 0.99 & 1.00 & 1.00 & 1.00 & 1.00 & 1.00 & 1.00 & 0.85 & 1.00 & 1.00 & 0.95 & 1.00 & 1.00 & 0.95 & 1.00 & 0.88 & 1.00 & 0.86 \\
France & 1.00 & 1.00 & 1.00 & 0.98 & 1.00 & 1.00 & 0.93 & 1.00 & 0.97 & 0.95 & 1.00 & 1.00 & 0.94 & 1.00 & 0.92 & 0.89 & 0.78 & 0.82 \\
Italy & 0.79 & 0.85 & 0.90 & 0.92 & 0.90 & 0.86 & 0.81 & 0.83 & 0.83 & 0.77 & 0.77 & 0.73 & 0.68 & 0.63 & 0.52 & 0.48 & 0.37 & 0.39 \\
USA & 0.85 & 0.82 & 0.76 & 0.80 & 0.83 & 0.83 & 0.81 & 0.88 & 0.89 & 0.85 & 0.93 & 1.00 & 1.00 & 1.00 & 0.95 & 1.00 & 0.86 & 0.91 \\
Canada & 1.00 & 1.00 & 0.97 & 0.96 & 0.95 & 0.96 & 0.94 & 0.96 & 1.00 & 0.96 & 1.00 & 1.00 & 1.00 & 1.00 & 0.76 & 0.87 & 0.65 & 0.52 \\
Spain & 0.62 & 0.63 & 0.58 & 0.54 & 0.55 & 0.56 & 0.53 & 0.55 & 0.52 & 0.57 & 0.63 & 0.58 & 0.57 & 0.53 & 0.44 & 0.44 & 0.30 & 0.31 \\
\hline
\end{tabular}

*Efficiency scores based on intertemporal DEA

To sum up, different conclusions on the performance of all members in the sample can be drawn from the kernel analysis. Firstly, while improvement in labor productivity and technology has taken place, efficiency levels have gone down. This is not surprising if one considers that purchase of superior technology usually involves efficiency level deterioration initially. On the other hand, it also implies the creation of opportunities to benefit from new leader spillovers at the future. Secondly, heterogeneity has increased in labor productivity as well as in technology and efficiency between these OECD countries during the analysed period. Thirdly, the three variables have evolved from unimodality to bimodality, finally showing distributions with two clubs. On one hand, USA, Finland and France evolve to a club with higher labor productivity and efficiency level, while Canada, Italy and Spain end up in the club of lower levels in these variables. On the other hand, USA and France, followed by Italy and Spain, use higher capital/labor technologies, while Finland and Canada integrate a less capital-intensive group. These capital/labor differences could be explained by a different pattern of industrial specialization within this ICT sector (Note 19), but the analysis of these field overpass our present task.

\section{Conclusions}

Following the theoretical framework of Basu and Weil (1998) and Los and Timmer (2005), this article has applied a kernel analysis to study convergence paths in the ICT-producing manufacturing industry of six developed countries within the two last decades of the $20^{\text {th }}$ century. This is the first study that applies this theoretical framework and non-parametric methods to the ICT sector, a relevant industry in the transition of the two centuries. Due to the nature of this industry, special attention was paid to variables measurement by using hedonic deflators and unit value ratios to reach accurate international comparison over time.

The application of kernel analysis has allowed us to observe convergence patterns of these countries in terms of labor productivity, technology and efficiency. This analysis offers a more accurate methodology to explore different convergence concepts (homogenization and catch-up), in the same way that information on intra-distribution mobility and distribution shape. In the cases of labor productivity and efficiency, distributions move from a unimodal distribution towards a bimodal distribution over time, with two clubs of countries at the beginning of the $21^{\text {th }}$ century: the first group containing USA, France and Finland, with high productivity and efficiency levels; while the second group is formed by Canada, Italy and Spain, with low productivity and efficiency levels. In terms of technology, their distribution also moves from a unimodal to a bimodal distribution: Finland and Canada belong to the low capital-intensity club, while the high-medium capital intensity club is formed by USA and France (with the highest levels), together with Italy and Spain.

According to the obtained results, a pattern of industrial specialization should be selected based on a Basu and Weil type of model augmented with non-immediate spillover. On the one hand, the economic policy design have to consider that the selection of capital -intensive technologies extends the possibilities of spillovers from the innovative leader, provided that the country has the complementary actives to benefit from those. Although, in the short run, more costly in terms of relative efficiency losses, this option will increase the growth rates of the country and will drive the efficiency convergence with the leader in the future. If the country does not have those actives, the development of them should be a policy task because the absence of them will diminish the spillovers assimilation possibilities.

On the other hand, policy-decision makers should be aware that the selection of less capital-intensive technologies, more appropriate with the actives (human capital, labor skills, technology capital, institutions, complementary industries...) owned by the country, although less costly in terms of relative efficiency in the 
short run, will cut the assimilation possibilities of the spillovers stemming from the innovative leader, as well as the growth rates of the country in the long run.

What is the reason behind the appearance of these different clubs? The answer to this question is worth to become the matter of future research. Different endowments of human capital and R\&D, complementary industries, as well as country institutions and regulations may be good candidates for future explanations. Data limitations for the analysed period, due to the especial character of the ICT industry, have also limited the research to more countries and a longer period. Availability of a larger sample, in terms of countries and years, will allow us to deepen the ultimate determinants of the different clubs in the future.

\section{References}

Abramovitz, M. (1986). Catching up, forgoing ahead and falling behind. In M. Abramovitz (Ed.), Thinking about growth. And other essays on economic growth and welfare (pp. 220-242). Cambridge: Cambridge University Press. http://dx.doi.org/10.1017/S0022050700046209

Abramovitz, M. (1994). Catch-up and convergence in the postwar growth boom and after. In W. J. Baumol, R. R. Nelson, \& E. N. Wolff (Eds.), Convergence of Productivity, Cross-National Studies and Historial Evidence (pp. 86-125). Oxford: Oxford University Press.

Aghion, P., \& Howitt, P. (1998). Endogenous Growth Theory. Cambridge, MA: MIT Press

Aghion, P., \& Howitt, P. (2006). Appropriate Growth Policy, Shumpeter Lecture. Journal of the European Economic Association, Papers and Proceedings. http://dx.doi.org/10.1162/jeea.2006.4.2-3.269

Atkinson, A. B., \&, Stiglitz, J. (1969). A New View of Technological Change. Economic Journal, 79, 573-578. http://dx.doi.org/10.2307/2230384

Barro, R. J., \& Sala-i-Martín, X. (1991). Convergence across states and regions. Brookings Papers on Economic Activity, 1, 107-182. http://dx.doi.org/10.2307/2534639

Barro, R. J., \& Sala-i-Martín, X. (1992). Convergence. Journal of Political Economy, 100, 223-251. http://dx.doi.org/10.1086/261816

Barro, R. J., \& Sala-i-Martín, X. (1995). Economic Growth. NewYork: Mcgraw Hill.

Basu, S., \& Weil, D. N. (1998). Appropriate Technology and Growth. Quartely Journal of Economics, 113, 1025-1054. http://dx.doi.org/10.1162/003355398555829

Baumol, W. (1986). Productivity growth, convergence and welfare: What the log run data show. American Economic Review, 76, 1072-1085.

Baumol, W. J., Nelson, R. R., \& Wolff, E. N. (1994). Convergence of productivity. Oxford: Oxford University Press.

Baumol, W., \& Wolff, E. N. (1988). Productivity growth, convergence and welfare: replay. American Economic Review, 78, 1155-1159.

Bernard, A. B., \& Jones, C. I. (1996a). Comparing Apples to Oranges: Productivity Convergence and Measurement across Industries. American Economic Review, 86, 1216-1238.

Bernard, A. B., \& Jones, C. I. (1996b). Technology and Convergence. The Economic Journal, 106, 1037-1044. http://dx.doi.org/10.2307/2235376

Bernard, A. B., \& Jones, C. I. (1996c). Productivity across industries and countries: time series theory and evidence. The Review of Economics and Statistics, 78, 135-146. http://dx.doi.org/10.2307/2109853

Charnes, A., Cooper, W., \& Rhodes, E. (1978). Measuring the Efficiency of Decision-Making Units. European Journal of Operational Research, 2, 429-444. http://dx.doi.org/10.1016/0377-2217(78)90138-8

Cooper, W. W., Seiford, L. M., \& Zhu, J. (2004a). Handbook on Data Envelopment Analysis. New York: Springer. http://dx.doi.org/10.1007/b105307

Cooper, W. W., Seiford, L. M., \& Zhu, J. (2004b). Data envelopment analysis. Massachusetts: Kluwer. http://dx.doi.org/10.1007/1-4020-7798-X_1

Delgado-Rodríguez, M. J., \& Álvarez-Ayuso, I. (2008). Economic Growth and Convergence of EU Member States: An Empirical Investigation. Review of Development Economics, 12, 486-497. http://dx.doi.org/10.1111/j.1467-9361.2008.00440.x 
Diewert, E. (2008). What Is To Be Done for Better Productivity Measurement?. International Productivity Monitor, 16, 41-52.

Dollar, D., \& Wolff, E. N. (1994). Capital intensity and TFP convergence by industry in manufacturing, 1963-1985. In W. J. Baumol, R. R. Nelson, \& E. N. Wolff (Eds.), Convergence of Productivity, Cross-National Studies and Historial Evidence (pp. 197-224). Oxford: Oxford University Press.

Dowrick, S., \& Nguyen, D. (1989). OECD comparative economic growth 1950-1985: catch-up and convergence. American Economic Review, 79(5), 1010-1030.

Durlauf, S. N., \& Quah, D. T. (1999). The new empirics of economic growth. In J. Taylor, \& M. Woodford (Eds.), Handbook of Macroeconomics (Vol. 1A). Amsterdam: North-Holland. http://dx.doi.org/10.1016/S1574-0048(99)01007-1

Färe, R. S., Grosskopf, S., Norris, M., \& Zhang, Z. (1994). Productivity Growth, Technical Progress and Efficiency Change in Industrialized Countries. American Economic Review, 84(1), 66-83.

Färe, R., S., Grosskopf, S., \& Margaritis, D. (2006). Productivity Growth and Convergence in the European Union. Journal of Productivity Analysis, 25, 111-141.http://dx.doi.org/10.1007/s11123-006-7134-x

Farrell, M. J. (1957). The measurement of productivity efficiency, Journal of the Royal Statistical Society (Series A), 120, 253-290. http://dx.doi.org/10.2307/2343100

Freeman, C., \& Louça, F. (2001). As Time Goes by. From the Industrial Revolutions to the Information Revolution. Oxford: Oxford University Press.

Giménez, G. (2006). Investment in new technology: Modelling the decision process. Technovation, 26, 345-350. http://dx.doi.org/10.1016/j.technovation.2005.03.008

Henderson, D. J., \& Russell, R. R. (2005). Human Capital and Convergence: A Production-frontier Approach. International Economic Review, 46, 1167-1205. http://dx.doi.org/10.1111/j.1468-2354.2005.00364.x

Hodrick, R., \& Prescott, E. (1997). Post-war US Business cycles: An Empirical Investigation. Journal of Money, Credit and Banking, 29, 1-16. http://dx.doi.org/10.2307/2953682

Howitt, P. (2000). Endogenous growth and cross-country income differences. American Economic Review, 90, 829-846. http://dx.doi.org/10.1257/aer.90.4.829

Inklaar, R., \& Timmer, M. (2007). International comparisons of Industry Output, Inputs and Productivity Levels: Methodology and New Results. Economic System Research, 19, 343-364. http://dx.doi.org/10.1080/09535310701572040

Inklaar, R., \& Timmer, M. (2009a). Measurement error in cross-country productivity comparisons: Is more detailed data better?. Groningen Growth and Development Centre Research, Memorandum (p.112).

Inklaar, R., \& Timmer, M. (2009b). Productivity Convergence across Industries and Countries: The Importance of Theory-based Measurement. Macroeconomic Dynamics, 13(52), 218-240. http://dx.doi.org/10.1017/S1365100509090117

Inklaar, R., O'Mahony, M., \& Timmer, M. (2003). ICT and Europe's productivity performance: Industry-level and Growth Accounting comparisons with the United States. Groningen Growth and Development Centre Research, Memorandum, GD-68.

Islam, N. (2003). What have we learnt from the convergence debate?. Journal of Economic Surveys, 17(3), 309-362. http://dx.doi.org/10.1111/1467-6419.00197

Krüger, J. J., Cantner, U., \& Hanusch, H. (2000). Total Factor Productivity, the East Asian Miracle, and the World Production Frontier. WeltwirtschaftlichesArchiv, 1361(1), 111-136

Kumar, S., \& Russell, R. R. (2002). Technological Change, Technological Catch-up and Capital Deepening: Relative Contributions to Growth and Convergence. American Economic Review, 92, 527-548. http://dx.doi.org/10.1257/00028280260136381

Lall, P., Featherstone, A., \& Norman, D. (2002). Productivity Growth in the Western Hemisphere (1978-94): The Caribbean in Perspective. Journal of Productivity Analysis, 17, 213-231. http://dx.doi.org/10.1023/A:1015008020851

López-Pueyo, C., \& Mancebón, M. J. (2010). Innovation, Accumulation and Assimilation: Three Sources of Productivity Growth in ICT Industries. Journal of Policy Modeling, 32(2), 268-285. http://dx.doi.org/10.1016/j.jpolmod.2010.02.003 
Los, B., \& Timmer, M. P. (2005). The 'Appropriate Technology' Explanation of Productivity Growth Differentials: An Empirical Approach. Journal of Development Economics, 77, 517-531. http://dx.doi.org/10.1016/j.jdeveco.2004.04.001

Margaritis, D., Färe, R., \& Grosskopf, S. (2007). Productivity, Convergence and Policy: A Study of OECD Countries and Industries. Journal of Productivity Analysis, 28(1-2), 87-105. http://dx.doi.org/10.1007/s11123-007-0044-8

Maudos, J., Pastor, J. M., \& Serrano, L. (2000). Convergence in OECD countries: technical change, efficiency and productivity. Applied Economics, 32, 757-765. http://dx.doi.org/10.1080/000368400322381.

Nicolini, R. (2011). Labour productivity in Spain: 1977-2002. Applied Economics, 43, 465-485. http://dx.doi.org/10.1080/00036840903427216

O'Mahony, M., \& van Ark, B. (2003). EU Productivity and Competitiveness: An Industry Perspective. Can Europe resume the catching up process?. Report to the European Commission. National Institute for Economic and Social Research.

OECD. (2001). Measuring Productivity.Measurement of aggregate and industry-level productivity growth, Paris: OECD.

OECD. (2003). Sources of Economic Growth in OECD. Paris: OECD.

Pérez, C. (2002). Technological Revolutions and Financial Capital. The Dynamics of Bubles and Golden Ages. Edward Elgar Publishing.

Pilat, D., \& Lee, F. (2001). Productivity Growth in ICT-producing and ICT-using industries: A Source of Growth Differentials in the OECD. OECD Science, Technology and Industry Working Papers 4. http://dx.doi.org/10.1111/j.1475-4991.1996.tb00161.x

Pilat, D., \& Prasada, R. D. S. (1996). Multilateral comparisons of output, productivity and purchasing power parities in manufacturing. Review of Income and Wealth, 42(2), 113-130. http://dx.doi.org/10.1111/j.1475-4991.1996.tb00161.x

Pilat, D., Lee, F., \& van Ark, B. (2002). Production and Use of ICT: A Sectorial Perspective on Productivity Growth in the OECD Area. Paris: OECD Economic Studies.

Quah, D. T. (1993a). Empirical cross-section dynamics in economic growth, European Economic Review, 37 (1/2), 426-434. http://dx.doi.org/10.1016/0014-2921(93)90031-5

Quah, D. T. (1993b). Galton's Fallacy and the test of the Convergence Hypothesis. Scandinavian Journal of Economics, 95 (4), 427-443. http://dx.doi.org/10.2307/3440905

Quah, D. T. (1996a). Regional convergence clusters across Europe. European Economic Review, 40, 951-958. http://dx.doi.org/10.1016/0014-2921(95)00105-0.

Quah, D. T. (1996b). Empirics for economic growth. European Economic Review, 40, 1353-1375. http://dx.doi.org/10.1016/0014-2921(95)00051-8

Quah, D. T. (1996c). Twin Peaks: Growth and Convergence in Models of Distribution Dynamics. Economic Journal, 106, 1045-1055. http://dx.doi.org/10.2307/2235377

Quah, D. T. (1997). Empirics for growth and Distribution: Stratification, Polarization and Convergence Clubs. Journal of Economic Growth, 2, 27-59. http://dx.doi.org/10.1023/A:1009781613339

Salinas-Jiménez, M. M. (2003). Technological change, efficiency gains and capital accumulation in labour productivity growth and convergence: an application to the Spanish regions. Applied Economics, 35, 1839-1851. http://dx.doi.org/10.1080/000368403100016289800

Salinas-Jiménez, M. M., Álvarez-Ayuso, I., \& Delgado-Rodríguez, M. J. (2006). Capital accumulation and TFP growth in the EU: A production frontier approach. Journal of Policy Modeling, 28, 195-205. http://dx.doi.org/10.1016/j.jpolmod.2005.07.008

Scarpetta, S., Bassanini, A., Pilat, D., \& Schreyer, P. (2000). Economic Growth in the OECD Area: Recent Trends at the Aggregate and Sectoral Level. OECD Economics Department Working Paper, 248.

Shestalova, V. (2003). Sequential Malmquist Indices of Productivity Growth: An Application to OECD Industrial Activities. Journal of Productivity Analysis, 19, 211-222. http://dx.doi.org/10.1023/A:1022857501478 
Silverman, B. (1986). Density Estimation for Statistics and Data Analysis. Monographs on Statistics and Applied Probability. London: Chapman and Hall/CRC.

Solow, R. M. (1956). A Contribution to the Theory of Economic Growth. Quarterly Journal of Economics, 70, 65-94. http://dx.doi.org/10.2307/1884513

Taskin, F., \& Zaim, O. (1997). Catching-up and Innovation in High and Low Income Countries. Economic Letters, 54, 93-100. http://dx.doi.org/10.1016/S0165-1765(97)00004-9

Temple, J. (1999). The new growth evidence, Journal of Economic Literature, 37, 112-156. http://dx.doi.org/10.1257/jel.37.1.112

Thanassoulis, E. (2001). Introduction to the Theory and Application of Data Envelopment Analysis. Massachusetts: Kluwer Academic Publishers.

Timmer, M. P., \& Los, B. (2005). Localized Innovation and Productivity Growth in Asia: An Intertemporal DEA Approach. Journal of Productivity Analysis, 23, 47-64. http://dx.doi.org/10.1007/s11123-004-8547-z

Triplet, J. (2004). Handbook on Hedonic Price Indexes and Quality Adjustments in Price Indexes: Special Application to Information Technology Products. STI OECD Working Paper 9.

Tulkens, H., \& Van den Eeckaut, P. (1995). Non-parametric Efficiency, Progress and Regress Measures for Panel Data: Methodological Aspects. European Journal of Operational Research, 80, 474-499. http://dx.doi.org/10.1016/0377-2217(94)00132-V.

Van Ark, B., \& Timmer, M. (2001). PPPs and international productivity comparisons: bottlenecks and new directions. ILO Seminar on Productivity Comparisons and Joint World Bank Seminar on Purchasing Power Parities.

Villaverde, J., \& Maza, A. (2008). Productivity convergence in the European regions, 1980-2003: a sectoral and special approach. Applied Economics, 40, 1299-1313. http://dx.doi.org/10.1080/00036840600771361

Wand, M. P., \& Jones, M. C. (1995). Kernel Smoothing. London: Chapman and Hall.

\section{Notes}

Note 1. See Pérez (2002) and Freeman and Louça (2001).

Note 2. In this paper, it is considered that two countries have a similar technology (in the sense of Basu and Weil, 1998) when they have the same capital/labor ratio.

Note 3. Data Envelopment Analysis (DEA) is a non-parametric methodology introduced by Charnes, Cooper and Rhodes (1978) to calculate efficiency in productive organizations through the solution of mathematical programming problems. For an excellent article using DEA to decompose the growth of labor productivity and analysing beta convergence in OECD countries see Maudos et al. (2000). Up to our knowledge, Los and Timmer (2005), Timmer and Los (2005) and Henderson and Russell (2005) were the only ones who apply an intertemporal frontier to obtain the decomposition of labor productivity growth and to calculate the efficiency scores, but all of them work at aggregate level.

Note 4. Dowrick and Nguyen (1989), Dollar and Wolff (1994), Abramovitz (1994), and Bernard and Jones (1996b, 1996c), among others.

Note 5. Taskin and Zaim(1997), Maudos et al.(2000), Kumar and Russell (2002), Lall et al. (2002), Los and Timmer (2005), Timmer and Los (2005), Henderson and Russell (2005), Färe et al.(2006), Salinas-Jiménez et al. (2006), Margaritis et al. (2007) and Delgado-Rodríguez and Álvarez-Ayuso (2008).

Note 6. Others studies using kernel analysis to study convergence processes undergone by Spanish and European regions are those of Salinas-Jiménez (2003) and Nicolini (2011), and Villaverde and Maza (2008), respectively.

Note 7. Timmer and Los (2005) explain this hypothesis on the basis of an illustrative example referred to different appropriateness of technological advances in means of transport (bicycle, train and high-speed train).

Note 8. Atkinson and Stiglitz (1969) originally introduced the term "localized innovation".

Note 9. Giménez (2006) develops a model in which learning cost is a crucial determinant to explain the decision to invest in new technology.

Note 10. Baumol, Nelson and Wolff (1994) offer a comprehensive analysis on the significance of different concepts of convergence. About studies on convergence with rich or highly productive countries see the surveys of Temple (1999), Durlauf and Quah (1999) or Islam (2003). 
Note 11. Silverman (1986) analyses these methods: the naïve estimator, the nearest neighbour method, the variable kernel method, the orthogonal series estimators and the maximum penalized likelihood estimators.

Note 12. The methodological background of the Kernel Density Estimation is described in detail in Silverman (1986) and Wand and Jones (1995). The estimation will be obtained with EViews 6.

Note 13. Empirical estimations of EFI will be obtained with LINGO 11 programming mathematical-model solver.

Note 14. For a theoretical comparison between UVR and PPP (Purchasing Power Parity), see Pilat and PrasadaRao (1996) and van Ark and Timmer (2001). On the theory and practical application of hedonic prices in the IT and telecommunications sectors, see Triplett (2004) and O'Mahoney and Van Ark (2003).

Note 15. A detailed analytical and graphical explanation of this decomposition can be found in López-Pueyo and Mancebón (2010).

Note 16. This is true in an output - oriented approach. This approach is the more plausible assumption at macroeconomic level since achieving a social product as high as possible with a given resources endowmentinstead of realizing a giving product objective with a minimized amount of inputs- is closer to the objectives of growth policy (Krüeger et al.,2000).

Note 17. The application of kernel estimation to original data yields similar results, but the different scales in its axes make comparisons more difficult.

Note 18. The following simple rule is used for allocating countries: $i \in \mathrm{G}_{j}$ if $\mathrm{x}_{i} \in\left[\mathrm{c}_{i}, \mathrm{c}_{j+1}\right]$ for $\mathrm{j}=1,2$ where $\mathrm{c}_{j}$ are cut points defined as the values of $\mathrm{x}$ at which estimated density reaches a local minimum.

Note 19. Those countries specialized in those parts of ICT characterized by very quick technological progress shall have higher capital/labor ratios. 